\title{
Development of Physical Activity Models Based on Motor Perception for Kindergarten Children
}

\author{
B. Suhartini*, BM Wara Kushartanti
}

Department of Sports Science, State University of Yogyakarta, Indonesia

Received August 25, 2021; Revised December 22, 2021; Accepted January 16, 2022

\begin{abstract}
Cite This Paper in the following Citation Styles
(a): [1] B. Suhartini, BM Wara Kushartanti, "Development of Physical Activity Models Based on Motor Perception for Kindergarten Children," International Journal of Human Movement and Sports Sciences, Vol. 10, No. 1, pp. 6 - 13, 2022. DOI: 10.13189/saj.2022.100102.
\end{abstract}

(b): B. Suhartini, BM Wara Kushartanti (2022). Development of Physical Activity Models Based on Motor Perception for Kindergarten Children. International Journal of Human Movement and Sports Sciences, 10(1), 6 - 13. DOI: 10.13189/saj.2022.100102.

Copyright $(2022$ by authors, all rights reserved. Authors agree that this article remains permanently open access under the terms of the Creative Commons Attribution License 4.0 International License

\begin{abstract}
The phenomenon that occurs in today's children is the decreasing number of play activities that involve children's physical activity. This study aims to produce five models of motor perception activity to improve executive function in kindergarten students. This research was pursued by using the research \& development method. The research procedure consisted of four stages; Stage 1. Preliminary study $(\mathrm{N}=50)$; Stage 2. Development of 5 models of motor perception activity; Stage 3. Expert validation consists of lecturers $(\mathrm{N}=7)$ and teachers $(\mathrm{N}=3)$; and Stage 4. Trial of motor perception activity model $(\mathrm{N}=50)$. The data collection technique used was in the form of filling out observation sheets for 50 parents. Data analysis was summarized in the form of quantitative descriptive analysis and qualitative analysis. The results showed that children's motoric elements were low, including $15 \%$ student activity, $40 \%$ balance, $23 \%$ motor skills, $27 \%$ interest, and $57 \%$ attention. The availability of learning equipment to support motor perception activities is indicated by the percentage of $49 \%$ or very low. This motor perception activity model is created in 5 activities, namely: (1) walking on a balance beam, (2) jumping in a half circle of hola hops, (3) running, jumping, jumping \& tiptoeing, (4) crawling while dribbling, and (5) throwing balloons while sitting. Based on the results of the calculation of quantitative data from the teacher's assessment as the model user, it is known that the level of implementation of the motor perception activity model for kindergarten students is very high at $96.15 \%$ and the quality of the model is very high at $94.85 \%$. Through
\end{abstract}

quantitative and qualitative analysis, it is known that the motor perception activity learning model is suitable for use in learning physical activity for kindergarten students while at the same time giving an impact on children's physical activity participation.

Keywords Early Childhood, Development Model, Physical Activity, Play, Motor Perception

\section{Introduction}

Motion is used in almost all human activities. Through the dimensions of human motion, people try to knit a useful and meaningful life in various and diverse roles [1]. Many human activities involve motor dimensions, one of which is perceptual motor. Perceptual motor is the ability to interpret the stimulus received by the sense organs. Perceptual abilities are useful for understanding everything that is around, so that a person is able to do or take certain actions according to the situation at hand [2]. Efforts to develop perceptual motor are actually good to do through physical education, especially for school students. Perceptual motor development can be done through exercises in the form of movements that lead to the ability to understand the body, understand direction, understand space, and understand tempo [3]. These activities can be arranged and packaged in the form of games/plays, because the activities are fun, especially for children who are still in school. 
Children who have developed their perceptual motor skills can control their entire body, develop their body processing skills, are accustomed to healthy living, and are able to engage in social activities or interact with other people [4]. Children who are kinesthetically intelligent are able to use and combine their mind and body simultaneously to achieve certain goals. The process of optimizing motor perceptual abilities requires an environment that supports children to move freely and should be done outdoors. This activity is carried out with fun and meaningful play.

This situation is contrasted with the phenomenon that exists in early childhood at this time, namely the absence of a PE learning model, especially for developing kindergarten students, and the reduced play activity involving children's physical activity. When at home, children are filled with electronic games that tend to make children always only play the buttons instead of doing physical activities. According to the Play and Physical Quotient research conducted in several regions including Indonesia, the results show that Indonesian children rank the lowest in physical and play abilities because Indonesian children prefer to fill their playing time with reading books and playing computer activities. Parents who too often issue warnings and prohibitions if their children move too often. It can be concluded that from the two statements it is clear that parents also contribute greatly to the child's lack of gross motor activity. Parents in Indonesia prefer it if their children sit quietly in the house, without much movement.

This situation is exacerbated by the unconditioned learning activities in Kindergarten. Learning activities carried out in Kindergarten tend to be unplanned and aimless [5]. This worsens the motor perception stimulation program for children aged 3-6 years. Therefore, a program that is cheap and easy is needed to be implemented in Kindergarten with the conditions of educators with very diverse backgrounds. The learning model of motor perception activity is a play activity that can be programmed and aimed. The results of previous studies showed that Kindergarten students showed that in learning physical activity the teacher did not use a standard physical activity learning model, but children were given monotonous activities.

Children's motor skills closely related to the child's self-image or self-confidence [25]. Children who have better motor skills in sports will cause them to be appreciated by their friends. The role of motor skills in children also affects the child's encouragement can entertain him and get a feeling of pleasure. Like a child feeling happy with the skills to play computer, play soccer or playing electronic instruments or toys other. So the role of optimization early childhood motor skills needs done because this is bridge to development better [26].

\section{Materials and Methods}

\subsection{Research Design}

This study uses a Research \& Development research design [6]. The research procedure consisted of four stages; Stage 1. Preliminary study $(\mathrm{N}=50)$; Stage 2 . Development of 5 models of motor perception activity; Stage 3. Expert validation consists of lecturers $(\mathrm{N}=7)$ and teachers $(\mathrm{N}=3)$. Stage 4 . Trial of motor perception activity model $(\mathrm{N}=50)$.

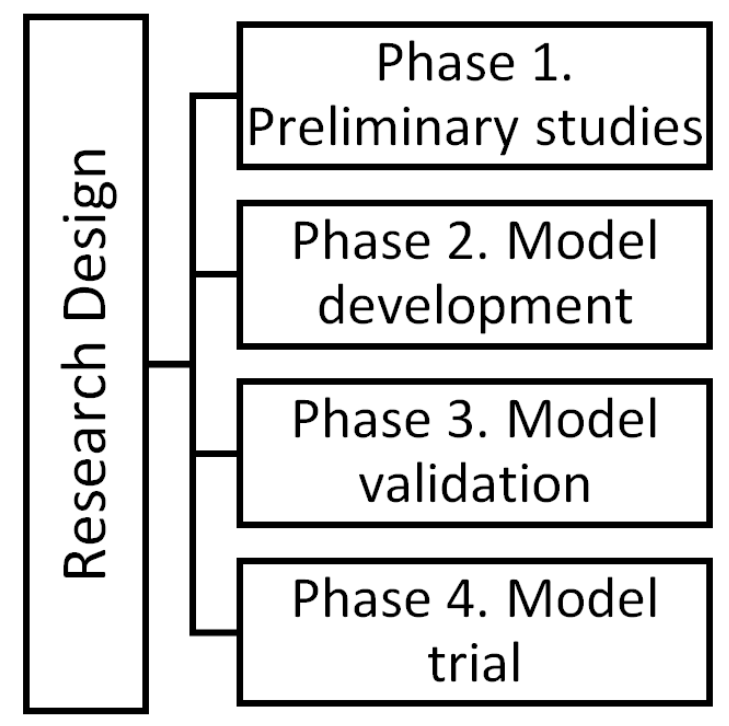

Figure 1. Flowchart of Research Design

\subsection{Participants}

The selection of participants in this study used purposive sampling. In the preliminary study stage, the participants were 50 parents of students. In the validation stage of the motor perception activity model, the participants were 7 experts from the lecturer element and 3 experts from the teacher element. In the trial phase of the motor perception activity model, the participants were 50 kindergarten students aged 5-6 years in Bantul Regency.

Table 1. Research Participants

\begin{tabular}{|c|c|c|}
\hline Phase & Description & Total \\
\hline Preliminary studies & Parents & 50 \\
\hline \multirow{2}{*}{ Model validation } & Lecturer & 7 \\
\cline { 2 - 3 } & Teacher & 3 \\
\hline Model trial & Kindergarten students & 50 \\
\hline
\end{tabular}




\subsection{Data Collection}

Data collection techniques regarding identity assisted by their parents include mother's knowledge about the development of executive function. Data on executive function development of kindergarten children with observations are made by teachers during learning in class and outside class.

\subsection{Data Analysis}

The data analysis technique used is quantitative descriptive analysis and qualitative analysis.

\section{Results}

Before producing the five models of motor perception activity, several preliminary phases have been carried out, namely the preliminary studies phase and the model development phase. Here is the order of the phases:

Phase 1. Preliminary Study. In the preliminary study, they carried out theoretical mapping related to motor perception activities for kindergarten children. Several theoretical foundations were obtained to develop a model of motor perception activity that can improve children's executive functions. In phase 1 , information was also explored about the characteristics of kindergarten students related to activity, physical balance, motor skills, interest in models, and attention. The researcher also found the teacher's understanding of what is meant by the motor perception activity model consisting of understanding, benefits, material development, and MPA instrument development. Finally, researchers are looking for information related to the availability of support for motor perception activity models consisting of equipment availability and equipment development. The data at phase 1 are used to construct a model of motor perception activity. The details of the results of the preliminary study are described in the following description.

\subsection{Descriptive Characteristics of Kindergarten Students'}

The results of interview data and observations in the field between researchers and physical education teachers about the characteristics that exist in kindergarten students in participating in Motor Perception Activity (MPA) learning, there are 5 elements consisting of: 1) Kindergarten student activity children in participating in PE learning; 2) Physical balance, both static and dynamic; 3) motor skills, complex motor coordination, and object control skills, motor perception that requires controlling awareness of time, space, energy (changes from slow to fast motion, or vice versa; changes to space, and power regulation); 4) interest in learning motor perception activities at school; and 5) about kindergarten students' attention to MPA learning. More details on the results of observations and interviews can be seen in Table 2:

Table 2. Kindergarten Students' Characteristics

\begin{tabular}{|c|c|}
\hline Characteristics & \% \\
\hline Student activity & $15 \%$ \\
\hline Physical balance & $40 \%$ \\
\hline Motoric skills & $23 \%$ \\
\hline Interest & $27 \%$ \\
\hline Attention & $57 \%$ \\
\hline
\end{tabular}

Based on the results of Table 2, it can be concluded that the characteristics of kindergarten students in participating in PE learning are that most kindergarten students are less active, have difficulty moving, are less happy, lack attention and half experience obstacles in their motor skills. Thus, kindergarten student teachers in PE learning need a physical activity learning model that aims to improve physical balance and attention from the executive function, namely focus, creativity, self-control, and logical thinking for kindergarten students.

\subsection{Description of Teachers' Understanding of MPA Model}

The results of the research related to the teacher's understanding of the understanding of the MPA learning model, the benefits of learning, how to develop MPA learning materials by playing, and how to develop an instrument for assessing learning outcomes, clearly can be seen in Table 3:

Table 3. Teachers' Understanding of MPA Model

\begin{tabular}{|c|c|c|c|c|}
\hline & High & Low & Easy & Difficult \\
\hline Understanding of MPA & $15 \%$ & $85 \%$ & & \\
\hline Benefit MPA & $30 \%$ & $70 \%$ & & \\
\hline Development MPA & & & $83 \%$ & $17 \%$ \\
\hline $\begin{array}{c}\text { Instrument } \\
\text { Development }\end{array}$ & & & $75 \%$ & $25 \%$ \\
\hline
\end{tabular}

Based on Table 3, it can be explained that most teachers do not understand the meaning of the MPA learning model and the benefits of the MPA learning model. In addition, teachers are also still experiencing difficulties in developing MPA material with games, and experiencing difficulties in developing an assessment instrument for kindergarten student outcomes, so teachers need an alternative MPA learning model for learning materials related to executive functions, namely focus, creativity, self-control, and logical thinking for students in accordance with the characteristics of kindergarten students and at the same time their evaluation.

\subsection{Availability of Motor Perception Activity Equipment}

The results of observations of equipment owned by 
kindergarten schools related to motor perception activity models are balls, goals, or activity support tools (hola hops, medicine balls, carpets, mattresses, soccer balls, bats, and so on) generally very limited. Overall the availability of learning equipment is very less. In addition, teachers also experience difficulties in developing motor perception activity model equipment. In detail, it can be seen in Table 4 below:

Table 4. Availability of MPA Model Equipment

\begin{tabular}{|c|c|c|c|c|}
\hline Availability & Less & Enough & Easy & Difficult \\
\hline Equipment & $88 \%$ & $12 \%$ & & \\
\hline $\begin{array}{c}\text { Equipment } \\
\text { development }\end{array}$ & & & $93 \%$ & $17 \%$ \\
\hline
\end{tabular}

Based on Table 4, regarding the availability of equipment, it can be concluded that the equipment for MPA model for kindergarten students is very lacking, and teachers have difficulty in developing physical education learning equipment that is suitable for the needs of kindergarten students in Bantul. So in this case, teachers need knowledge in terms of how to choose, modify and various examples of learning equipment that are suitable for the characteristics of kindergarten students. And have interest and benefit for students. For schools concerned to seek equipment that is not yet owned, so that for learning and MPA model are maximized and increased according to the learning objectives that are applied.

Phase 2. Model Development. The results of the preliminary study stage become recommendations for developing a model of motor perception activity. In this phase 2, five motor perception activities have been compiled that can be used by kindergarten students to develop basic movements in children's executive functions.

The development of the five MPA learning models obtained the posttest average value which was higher than the pretest average value. In addition, the MPA learning model is seen from the Wilcoxon statistical results p sig < 0.05 . So that it can be interpreted that there is a significant difference, it can be concluded that the MPA learning model is effective for improving children's executive functions. The following is a description of these five activities.

\section{Activity 1. Walking on the Balance Beam}

The aim is to increase the motor perception ability of the body's understanding of elements, the child mentions the limbs and while touching the body they touch, and improves balance, namely the development of children's equilibrium and tactile. Equilibrium is very important for balance when a child walks on a wooden catwalk or when doing motor activities. The benefits achieved from the movement are to train the child's focus when doing balance activities and the child's logical way of thinking when remembering the name of the picture and mentioning its function. Hula-hoop and pictures of limbs and catwalks.

\section{Activity 2. Jump In The Hola Hop Half Circle}

The goal is to improve leg muscles and improve the ability to jump with obstacles. The cross-lateral movement of crawling strengthens and integrates the two hemispheres of the brain and simultaneously coordinates the eyes, ears, hands, feet and increases spatial and tactile awareness. Also develop an understanding of space, namely when the child jumps and jumps between tools. Benefits: is to train children's focus when jumping and jumping, children must have good focus so they don't get out of the tool room, children's self-control must be able to control themselves so they are not too fast when jumping and jumping to the next tool. Equipment is prepared for colorful hula-hoop and stands.

\section{Activity 3. Run, Jump, Jump \& Tiptoe}

The goal is to improve children's jumping and jumping abilities to develop leg muscle strength, balance and increase awareness of direction. Benefits: It is training to focus on when the child jumps and jumps, self-control when predicting jumping and jumping in a limited space. The equipment prepared is 8 colorful hot hola hop.

\section{Activity 4. Creeping While Dribbling}

The goal is to increase the ability to crawl. This movement stimulates sensory-motor integration. Benefits: practice self-control, activities are carried out alternately, children should not jump in the queue, children's creativity in doing activities in various ways and directions) and focus on the time of doing activities, no one should miss and get out of the hula hoop circle.

\section{Activity 5. Throwing Balloons While Sitting}

The goal is to improve throwing ability and also improve hand-eye coordination. Benefits: is to train cooperation, increase focus, self-control, trying not to give up and a logical way of thinking. The equipment provided is hula-hoop and balloons.

Phase 3. Model Validation. In the third stage, an assessment of the motor perception activity model has been carried out by experts consisting of 7 lecturers and 3 teacher elements.

For the feasibility assessment of lecturer expert validation in assessing the motor perception activity model (MPA) to improve the executive function of kindergarten students who were assessed by 7 lecturers had 17 aspects of assessment and each aspect had 4 categories of assessment, namely: 1. Very unsafe/very not easy / very unpleasant / very impractical / not very optimizing / not very cheap / not very varied / very not integrative / not very suitable for the development of kindergarten students / very unattractive. 2. Not safe / not easy / not fun / not practical / not optimizing / not cheap / not varied / not integrative / not in accordance with the development of kindergarten / not interesting. 3. Safe / easy / fun / practical / optimizing / cheap / varied / integrative / according to the development of kindergarten 
students / interesting. 4. Very safe / very easy / very fun / very practical / very optimizing / very cheap / very varied / very integrative / very suitable for the development of kindergarten students / very interesting. Thus, for expert validation of lecturers in assessing the MPA model to improve students' executive functions a maximum score of 476 ( 17 aspects $x 4$ categories $x 7$ lecturers).

The assessment of the implementation of the model carried out by experts uses the Content Validity Ratio (CVR). The results of expert validation show an average answer rate of $88.66 \%$ with an average CVR calculation of 0.918 which means that the MPA learning model is relevant or good, and also has high content validity. On this basis, the five MPA activities are said to be good and content valid.

Based on the observations of 7 validators of lecturer expert validation, the results obtained are 422, if each validator gives a maximum value of 4 then the maximum number of values is 13 (aspects) $\mathrm{x} 4$ (classification) $\mathrm{x} 7$ (persons) $=476$, thus the percentage of observations of 7 (three) validators of kindergarten lecturers' expert validation is $88.66 \%$. The conclusion of the seven validators of the lecturer's expert validation stated that "the development of a MPA model to improve the executive function of kindergarten students is feasible".

Based on the observations of 3 validators, the opinion of kindergarten teachers obtained 154 results, if each validator gave a maximum value of 4 then the maximum number of values was 13 (aspects) $\times 4$ (classification) $\times 3$ (persons) $=156$, thus the percentage of the results observation of 3 (three) kindergarten teachers opinion validator is $98.72 \%$. The conclusion of the three validators of the opinion of kindergarten teachers stated that "the MPA model to improve the executive function of kindergarten students is feasible to use".

Phase 4. Model Testing. In the testing phase of the model, it is generally known that the implementation and quality of the MPA model obtained a score of $96.15 \%$ and $94.85 \%$, which means that the MPA model has a good level of implementation and quality. A summary of teacher assessments of the implementation and quality of MPA is presented in Table 5.

Table 5. Summary of Teachers' Assessment Implementation of MPA

\begin{tabular}{|c|c|c|c|c|}
\hline No & MPA & Score Max & N & \% \\
\hline 1 & Implementation of MPA & 104 & 100 & 96,15 \\
\hline 2 & Quality of MPA & 136 & 129 & 94,85 \\
\hline & Total & 240 & 229 & 95,42 \\
\hline
\end{tabular}

\section{Discussion}

Exercise and physical activity contained in the five motor perception activities, are not only beneficial for physical fitness, but also beneficial for healthy brain function, by increasing neurogenesis, synaptic plasticity, learning processes, and memory function [29]. Executive function which is developed through motor perception activity because it involves aspects of memory, attention, perception, language, and psychomotor function. Each aspect is a complex part, as in the memory aspect itself there is a process of encoding, storing, and retrieving information and can become short-term memory, long-term memory and working memory. On the aspect of attention can be selective, focused, divided, or continuous. Motor perception activity includes several levels of processes to recognize objects obtained from different sensory stimuli.

Five developed motor perception activities can prevent executive function decline. Poor executive function is also a predictor of mortality and can also be seen as a marker of health status. Physical activity has a beneficial influence on the executive function of early childhood. Activity is also one of the prevention efforts against executive function disorders. This opinion is reinforced by Baron [27] that through motor perception activities children get physical, cognitive, and social benefits. These activities include running, jumping, jumping, throwing and shaping.

\subsection{Phase 1. Preliminary Studies}

Based on the results of the research described previously, when viewed from the characteristics of kindergarten student learning activities, it is known that the results of the characteristics of kindergarten students in participating in PE learning are that most kindergarten students are less active, have difficulty moving, are less happy, less attentive and more than half experienced obstacles in motor skills. Thus, teachers of kindergarten students in PE learning need a physical activity learning model that aims to improve physical balance and attention as seen from the executive functions, namely focus, creativity, self-control, and logical thinking for kindergarten students.

The age of 3-6 years is a sensitive period or sensitive period in children, namely a period where a certain function needs to be stimulated, directed so that its development is not hampered [7]. For example, if the sensitive period for speaking in this period is not fulfilled, the child will have difficulty in language for the next period. Sensitive periods of children at this age include being sensitive to environmental regularities, exploring the environment with their tongue and hands, sensitive to walking, sensitive to small objects and details, and to social aspects of life [8].

Another opinion views the age period of 4-6 years as a phase of sense of initiative. In this period children should be encouraged to develop initiatives, such as the pleasure to ask questions from what they see, hear and feel [9]. If the child does not get obstacles from the environment, then the child is able to develop his initiative and creative power, as well as productive things in his favorite field.

Kindergarten students are less active in participating in PE subject learning because one of them is the lack of 
attractive physical activities made by classroom teachers, thus making kindergarten students not pay attention to learning [10]. This disinterest will have an impact on underdeveloped activities and executive functions of students, and in the end these students have low fitness levels, and this low fitness will result in these students being very susceptible to disease and low executive functions, namely focus, creativity, self-control, and logical thinking for students'[15].

Teachers who always help, give advice, and help do something even though children can do it themselves can prevent children from getting the opportunity to make mistakes or learn from those mistakes [11]. In this phase, whether or not the opportunity to take initiative is guaranteed (with the trust and independence that allows him to initiate), will grow the ability to take initiative. On the other hand, if too many are prohibited and reprimanded, the child will be filled with feelings of guilt and sin.

\subsection{Phase 2. Model Development}

In the development of the MPA model, it is known that this model is very important for children's physical and cognitive development [21]. Childhood is a very important and valuable phase, and is a period of formation in the period of human life (a noble and malleable phase of human life). Therefore, childhood is often seen as a golden period for the implementation of education. Childhood is a very fundamental phase for individual development because in this phase there is a very large opportunity for the formation and personal development of a person [12].

In kindergarten age children begin to group, learn to recognize the rules and work together with other friends. In addition to the above characteristics, children aged around 4-5 years will show curiosity and a strong enthusiasm for everything. Children have a strong sense of adventure (adventurousness). Children will pay a lot of attention, talk or ask about various things they have seen or heard [3].

At this kindergarten age, children also show a strong interest in observing the environment and objects around them, this urge makes children happy to go on trips to areas and children will be very observant when asked to look for something. Children aged 4-5 years still need a lot of physical activity. The need for children to perform various activities is necessary for the development of small and large muscles. These physical movements are not only important for developing physical skills, but can also have a positive effect on growing children's self-esteem and even cognitive development [1].

The success of children in mastering motor skills can make children proud of themselves. For example, a child is asked to walk on a catwalk. This activity requires the ability to balance and physical strength, movement alignment, courage, the ability to see the position of the board and the accuracy of placing the feet and emotional stability. If the child is able to pass the catwalk well, then in addition to developing his physical abilities, he also grows confidence in himself and develops his cognitive abilities [13]. A lot of physical activity in children encourages children to learn balance, courage, and harmony of movement [27].

Kindergarten education is one of the early childhood educations for children aged around 4-6 years. Kindergarten education has a very important role for the development of children's personalities, as well as to prepare them to enter the next level of education. By providing educational stimuli to help growth. The main task of kindergarten is to prepare children by introducing various knowledge, attitudes, behaviors, in a fun way. Kindergarten is a beautiful, comfortable, and happy place to play for children to socialize with their peers [14].

\subsection{Phase 3. Model Validation}

Based on expert validation of the MPA model, it is known that there has been a consensus among experts regarding the developed model. Judging from the consensus of the lecturers, it is known that the MPA model has high benefits and is safe for children to implement.

Judging from the teacher's understanding of the MPA learning model, it was found that most teachers did not understand the meaning of the MPA learning model and the benefits of the MPA learning model. In addition, teachers are also still experiencing difficulties in developing MPA material with games, and also experiencing difficulties in developing an assessment instrument for kindergarten student outcomes, so teachers need an alternative MPA learning model for learning materials related to executive functions, namely focus, creativity, self-control, and logical thinking for students in accordance with the characteristics of kindergarten students and at the same time their evaluation. The model is presented in the form of a guidebook and DVD, this will make it easier for teachers to understand the MPA learning model that will be applied to kindergarten students. Books can be read over and over again and DVDs can be seen directly, in more detail the movements and of course it will be clearer to learn.

PE teachers still apply the MPA learning model that is inserted or inserted into the game, and at the same time for brain stimulation according to the characteristics of kindergarten students [22]. This happens because firstly the teachers are not in their field, the second is that physical education teachers are classroom teachers, the basics for their PE is limited, so that their concept of learning activities and executive functions is very low. This is an obstacle in the field for teachers who teach PE [15].

According to the constructivist view driven by Piaget and Vygotsky, children are active and have the ability to build their knowledge. Mentally children construct their knowledge through reflection on their experiences [16]. Children acquire knowledge not by passively receiving it from others, but by actively building it themselves through interaction with their environment [17]. Children are active 
learning creatures who can create and build their knowledge.

Kindergarten age children are individual figures who are undergoing a very rapid development process and are very fundamental for the next life. Children have their own world and characteristics that are far different from the world and characteristics of adults [18]. Children are very active, dynamic, enthusiastic and almost always curious about what they see and hear, as if they never stop learning. From the environment children build knowledge, and high curiosity in children encourages children to find something new for themselves.

\subsection{Phase 4. Model Trial}

The trial results of the MPA model also show the success of the model in improving children's basic movements. This is influenced by the clarity of instructions and learning tools. The availability of learning equipment or media and the development of physical education learning equipment for kindergarten students mostly said it was lacking and only $12 \%$ said it was sufficient. This is one of the reasons why PE learning is less interesting, less varied learning programs, limited to monotonous activities [20]. Ideally, the school provides adequate learning equipment or media, with sufficient equipment to improve the quality of the teaching and learning process which in turn can improve student learning outcomes [25].

There are several reasons why it is important to use learning media in an effort to improve the quality of the process and student learning outcomes as well as the executive function of kindergarten students [23]. The main reason is related to the ability of the media to make abstract learning materials more concrete or real and clearer. As it is known that something that is learned will be more easily understood and remembered by kindergarten students if it is obtained through concrete experiences that involve many senses [19].

Other reasons related to the benefits that can be obtained through the use of the media itself, which include: 1) it can make the teaching and learning process more interesting and more interactive because the use of media can increase students' curiosity, positive attitude and motivation to learn. This can affect the mood of students to be happy; 2) can overcome the limitations of space, time, and senses because it can be used to manipulate objects; 3) can clarify, streamline the presentation of learning materials, with the media prepared in advance, many things can be considered and done to make the presentation of learning materials more interesting, clearer, more systematic, and more efficient [20].

\section{Limitations}

This research is not free from limitations. Researching human subjects, especially children, requires patience and thoroughness. In addition, the tools developed in motor perception activities are made of simple materials that do not harm students. Therefore, the quality of the tools used may have poor quality.

\section{Conclusions}

The five learning models of motor perception activities that have been developed have a high level of implementation and quality. The five models succeeded in having an impact on active participation in children. This is relevant to previous studies that motor perception activity can improve executive function in children.

\section{Conflict of Interest}

The author declares that he has no conflict of interests.

\section{REFERENCES}

[1] Asriansyah, A., \& Mahendra, A., "Model Permainan Perseptual Motorik Melalui Ban Motor Bekas Dalam Pendidikan Jasmani Pada Siswa Sekolah Dasar", Jendela Olahraga, 5(2), 122-130, 2020. https://doi.org/10.26877/j o.v5i2.6208

[2] Kurniawan, M. R., Syamsulrizal, S., Razali, R., \& Israwati, I., "The Ability of Gymnastics Motoric Perceptual Based on Local Culture for Early Childhood in Aceh Province", Budapest International Research and Critics in Linguistics and Education (BirLE) Journal, 3(2), 749-762, 2020. https://doi.org/10.33258/birle.v3i2.907

[3] Healy, A. F., Kole, J. A., Schneider, V. I., \& Barshi, I., "Training, retention, and transfer of data entry perceptual and motor processes over short and long retention intervals", Memory and Cognition, 47(8), 1606-1618, 2019. https://doi.org/10.3758/s13421-019-00955-Z

[4] Otero-Saborido, F. M., Vázquez-Ramos, F. J., Cenizo-Benjumea, J. M., \& González-Jurado, J. A. "Analysis of the assessment in Physical Education curricula in Primary Education", Sport, Education and Society, 2020. https://doi.org/10.1080/13573322.2020.1804349

[5] Hald, L. A., de Nooijer, J., van Gog, T., \& Bekkering, H., "Optimizing Word Learning via Links to Perceptual and Motoric Experience", Educational Psychology Review. Springer New York LLC, 2016. https://doi.org/10.1007/s1 0648-015-9334-2

[6] Gall, M.D., Gall, J.P., \& Borg, W.R., "Educational Research: An Introduction, 8th Edition", Educational An Introduction, 2009. Pg. 704.

[7] Chairilsyah, D., "Web-Based Application to Measure Motoric Development of Early Childhood", JPUD - Jurnal Pendidikan Usia Dini, 13(1), 1-14, 2019. https://doi.org/1 $0.21009 / 10.21009 /$ jpud.131.01 
[8] Zhou, Y., De Shao, W., \& Wang, L., "Effects of feedback on students' motor skill learning in physical education: A systematic review". International Journal of Environmental Research and Public Health. MDPI AG, 2021. https://doi.org/10.3390/ijerph18126281

[9] Haris Satria, Bangkit Seandi Taroreh, Margaretta Ineke Melynda, Novri Asri, "Play Activity: To Increase Fundamental Movement Skill for Children with Mild Mental Retardation", International Journal of Human Movement and Sports Sciences, 8(6A), 1-10, 2020. DOI: 10.13189/saj.2020.080701

[10] Rudd, J. R., Crotti, M., Fitton-Davies, K., O'Callaghan, L., Bardid, F., Utesch, T., Foweather, L., "Skill Acquisition Methods Fostering Physical Literacy in Early-Physical Education (SAMPLE-PE): Rationale and Study Protocol for a Cluster Randomized Controlled Trial in 5-6-Year-Old Children From Deprived Areas of North West England", Frontiers in Psychology, 11, 2020. https://doi.org/10.3389/ fpsyg.2020.01228

[11] Prieto, J. P., \& Herrero, D. C., "Perceptions of future teachers on motricity in early childhood education: An exploratory study with last-year students", Retos, (39), 155-162, 2021. https://doi.org/10.47197/retos.v0i39.78618

[12] Hidayati, A., Efendi, R., \& Saputra, A., "The quality of digital literation early childhood education teachers based on UNESCO standards", International Journal of Scientific and Technology Research, 9(3), 2020. 3514-3517

[13] Kok, M., Komen, A., van Capelleveen, L., \& van der Kamp, J., "The effects of self-controlled video feedback on motor learning and self-efficacy in a Physical Education setting: an exploratory study on the shot-put", Physical Education and Sport Pedagogy, 25(1), 49-66, 2020. https://doi.org/10.1080/17408989.2019.1688773

[14] Potdevin, F., Vors, O., Huchez, A., Lamour, M., Davids, K., \& Schnitzler, C., "How can video feedback be used in physical education to support novice learning in gymnastics? Effects on motor learning, self-assessment and motivation", Physical Education and Sport Pedagogy, 23(6), 559-574, 2018. https://doi.org/10.1080/17408989.2018.1485138

[15] Eva Julianti P, Yusmawati, Heni Widyaningsih, Abd. Halim, "Quality Physical Education Learning through Process Modeling Based on Kinesthetic Perception", International Journal of Human Movement and Sports Sciences, 9(1), 89-96, 2021. DOI: 10.13189/saj.2021.0901 12

[16] Marinšek, M., Jurak, G., \& Kovač, M., "Differences in Beliefs Regarding Physical Education Between Slovenian In-Service and Pre-Service Early Childhood Educators", Journal of Research in Childhood Education, 34(2), 251266, 2020. https://doi.org/10.1080/02568543.2019.167633 3

[17] Suwardi, S., "Evaluation of The Implementation Of Character Early Chilhood Education. Cakrawala Dini", Jurnal Pendidikan Anak Usia Dini, 9(1), 13-18, 2018. https://doi.org/10.17509/cd.v9i1.11346

[18] Estevan, I., Bardid, F., Utesch, T., Menescardi, C., Barnett, L. M., \& Castillo, I., "Examining early adolescents' motivation for physical education: associations with actual and perceived motor competence", Physical Education and Sport Pedagogy, 26(4), 359-374, 2021. https://doi.org/10. $1080 / 17408989.2020 .1806995$

[19] Caçola, P., \& Romero, M., "Strategies to Accommodate Children with Developmental Coordination Disorder in Physical Education Lessons", Journal of Physical Education, Recreation \& Dance, 86(9), 21-25, 2015. https://doi.org/10.1080/07303084.2015.1085341

[20] Nofi Marlina Siregar, Eka Fitri Novita Sari, Marlinda Budiningsih, Zulham, "The Basic Learning Model of Traditional Motion Based Games for Early Childhood (5-6) Years". International Journal of Human Movement and Sports Sciences, 9(1), 81-88, 2021. DOI: 10.13189/saj.202 1.090111

[21] Emyus, A. Z., Degeng, I. N. S., Setyosari, P., \& Ulfa, S. (2020). The influence of whole brain teaching (WBT) to the motoric and linguistic skills of preschoolers. International Journal of Instruction, 13(4), 799-814. https://doi.org/10.2 9333/iji.2020.13449a

[22] Nalbant, Ö. "Comparison of Physical and Motoric Features of Children Continuous the Sport School". Journal of Education and Training Studies, 5(13), 1, 2017 https://doi.org/10.11114/jets.v5i13.2863

[23] Bailey, J. O., Bailenson, J. N., Obradović, J., \& Aguiar, N. R. (2019). Virtual reality's effect on children's inhibitory control, social compliance, and sharing. Journal of Applied Developmental Psychology, 64. https://doi.org/10.1016/j.a ppdev.2019.101052

[24] Greenberg, L.M. \& Waldman, I.D. "Developmental normative data on the test of variables of attention (T.O.V.A.)". Journal of Child Psychology and Psychiatry. 34 (6): 1019- 1030, 2017. doi:10.1111/j.1469-7610.2013.t b01105.x. PMID 8408366

[25] Henry, L. \& Bettenay, C. "The assessment of executive functioning in children". Journal of Child and Adolescent Mental Health, 15(2), pp. 110-119, 2018. doi: $10.1111 / \mathrm{j} .1475-3588.2010 .00557$

[26] Rose SA, Feldman JF, Jankowski JJ. Implications of Infant Cognition for Executive Functions at Age 11. Psychological Science. 2012; 23(11):1345-1355. doi:10.1177/0956797612444902

[27] Baron IS, Kerns KA, Müller U, Ahronovich MD, Litman FR. Executive functions in extremely low birth weight and late-preterm preschoolers: effects on working memory and response inhibition. Child Neuropsychol. 2012; 18(6):586-99. doi: 10.1080/09297049.2011.631906. Epub 2011 Nov 28. PMID: 22122351.

[28] Traverso, L., Viterbori, P., \& Usai, M. C. "Improving executive function in childhood: evaluation of a training intervention for 5-year-old children". Frontiers in psychology, 6, 525, 2015. https://doi.org/10.3389/fpsyg.20 15.00525

[29] Ruffini C, Spoglianti S, Bombonato C, Bonetti S, Di Lieto MC, Pecini C. "Dialogic Reading to Empower Executive Functions in Preschoolers". Children (Basel). 2021;8(5):373, 2021 May 9. doi:10.3390/children8050373. 